\title{
Children at Risk of Poor Educational Outcomes: Theoretical Concepts and Empirical Results
}

\author{
Marcus Hasselhorn • Sabine Andresen • \\ Birgit Becker • Tanja Betz • \\ Marianne Leuzinger-Bohleber • Johanna Schmid
}

Published online: 14 September 2014

(C) Springer Science+Business Media Dordrecht 2014

A substantial proportion of children in western countries do not acquire the level of achievement in literacy, mathematics or science required to participate effectively in today's knowledge-based society (OECD 2006, 2010). These children also face a disproportionally high risk to fall behind their age-appropriate class, to be on a low educational track, to attain only a low educational qualification or even to drop out of school without any formal qualification. Different disciplines have studied these "children at risk of poor educational outcomes" using various concepts and methodological approaches. The aim of this special issue is to bring together these various perspectives and therefore to provide a more comprehensive picture of the diverse "risk factors" that are associated with poor educational outcomes. Theoretical as well as empirical contributions are included.

The first paper in this special issue by Marcus Hasselhorn et al. provides a systematic overview of the most important risk factors of poor educational outcomes

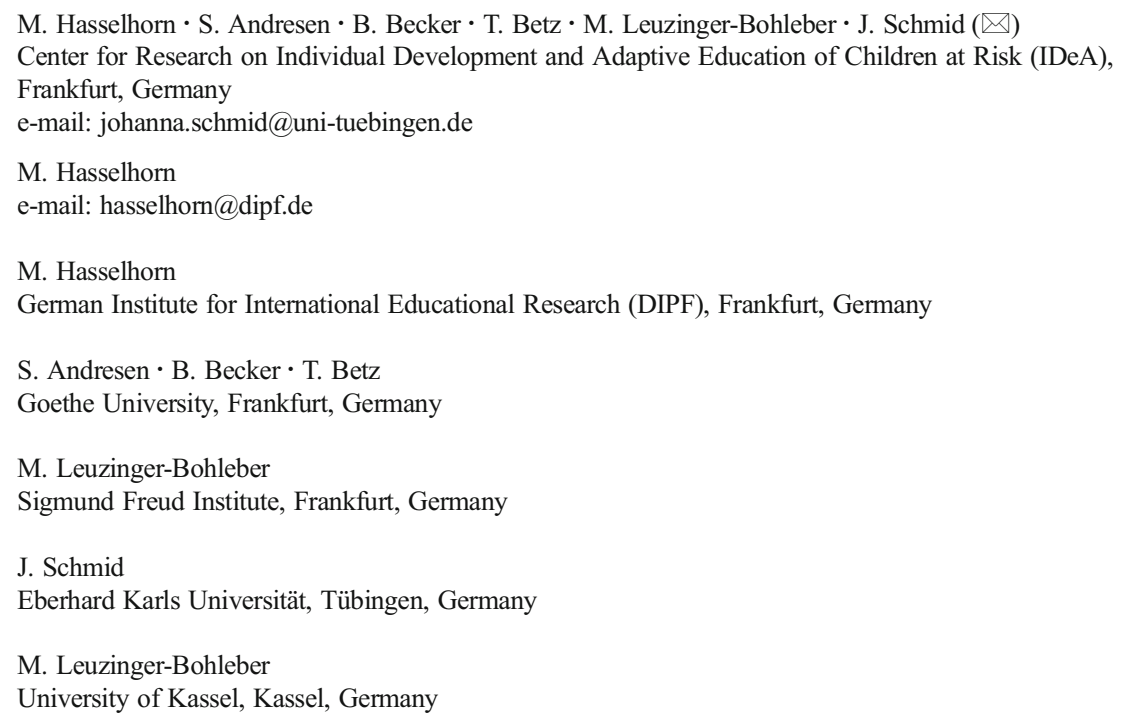


integrating multiple scientific perspectives. The following four papers focus on a specific discipline and describe the concept of "children at risk of poor educational outcomes" from the respective disciplinary perspective. The first of these theoretical papers by Sabine Andresen is based on the theory of childhood. She uses the concept of vulnerability as an analytic category to be applied in childhood studies and develops a taxonomy that differentiates between system-related and structural dimensions. The next paper by Birgit Becker and Julia Tuppat takes a sociological perspective and locates the concept of "children at risk of poor educational outcomes" within the broader concept of social inequality (see Becker and Tuppat 2013). Marianne Leuzinger-Bohleber addresses socio-emotional risk factors and focuses on attachment and mentalizing as two independent adaptive achievements which are essential for different functions. The last of the theoretical papers by Johanna Schmid and Marcus Hasselhorn takes a (neuro-) cognitive perspective and discusses three strands of literature related to (neuro-) cognitive risks of poor educational outcomes: intelligence research, research on working memory, and research on attentional processes.

The subsequent review of Johanna Lundqvist locates research in educational settings incorporating responses from children with or without disabilities or special educational needs, and describes how this kind of research was conducted. She offers implications for theory and practice.

The following eight papers of this special issues report on empirical studies on children at risk of poor educational outcomes in various disciplines. Tanja Betz reconstructs notions of risks in political reports on children and childhood. She uses a discourse analysis approach to evaluate the construction of risks in 16 current federal-level political reports on children and childhood in Germany and finds different construction of risk. The paper of Dagmar Duzy, Elmar Souvignier, Jan-Henning Ehm and Andreas Gold compares the development of decoding speed and reading comprehension from grade 1 to grade 3 in children with German as a second language and native German speaking children. The study shows a substantial achievement gap between these two groups of children. The next paper by Caterina Gawrilow, Anika Fäsche, Lena Guderjahn, Catherine Gunzenhauser, Julia Merkt and Antje von Suchodoletz investigates whether self-regulation predicts mathematical achievements in preschool age. They operationalize self-regulation abilities with different paradigms and find positive associations with children's early math skills. Angela Grimm and Petra Schulz compare monolingual and early second language learners regarding the prevalence of risk factors and (mis)diagnosis of Specific Language Impairment (SLI). They show that diagnosing SLI correctly is difficult in both monolinguals and in early second language learners, and correctly diagnosing children as being unimpaired tends to be more challenging in early second language learners. The paper of Denise Frawley, Selina McCoy, Joanne Banks and Maeve Thornton examines self-concept among boys and girls in Irish primary schools. Their findings reveals that boys are more likely than girls to score significantly lower on measures of 'good' behaviour and intellectual school status, while girls score significantly lower on freedom from anxiety than boys. Moreover there are associations with working class affiliation and special educational needs.

Erica Nordlander and Helena Olofsdotter Stensöta examine adolescents' subjective well-being in Sweden and investigate how it is related to school performance, gender and class origin. Their findings emphasize the importance of gender when studying the association between subjective well-being and class origin. In the paper from Jung Jin 
Lim, Sun Hee Ahn and Yeon Ha Kim the associations between quality of childcare and years of childcare exposure with school readiness of 5-year-old children in South Korea living in poverty is analyzed. The quality of childcare practices is positively associated with the children's learning related social skills, story comprehension abilities, and fine motor skills. The duration of ECEC however is not linked to either learning-related social skills or fine motor skills. The last paper by Pia Schober and Katharina Spieß examines how disadvantaged children aged zero to six years (e.g., children of low income parents or with migration background) differ from other less disadvantaged groups in their use of early childhood education activities and care arrangements in Germany and to what extent supply and demand side explanations can account for the observed disparities (see Schober and Spieß 2013). They find lower attendance rates of disadvantaged children especially in non-formal education participation.

Overall, the papers of this special issue contribute to a better understanding of the factors associated with a high risk of poor educational outcomes by combining different disciplinary perspectives and methodological approaches. This research can also help to identify opportunities to reduce the detrimental ramifications of these risk factors.

\section{References}

Becker, B., \& Tuppat, J. (2013). Unequal distribution of educational outcomes between social categories: 'Children at risk' from a sociological perspective. Child Indicators Research, 6(4), 737-51. doi:10.1007/ s12187-013-9190-x.

OECD (2006). Assessing science, reading and mathematical literacy: A framework for PISA 2006. Paris: OECD Publishing.

OECD (2010). PISA 2009 results: learning trends - Changes in student performance since 2000 (Vol. V). Paris: OECD Publishing.

Schober, P. S., \& Spieß, C. K. (2013). Early childhood education activities and care arrangements of disadvantaged children in Germany. Child Indicators Research, 6(4), 709-35. doi:10.1007/s12187-0139191-9. 